\title{
Minimally invasive video-assisted thyroidectomy versus conventional thyroidectomy: A single-blinded, randomized controlled clinical trial
}

\author{
Gouda M El-Labban \\ Department of Surgery, Faculty of Medicine, Suez Canal University, Ismailia, Egypt
}

Address for correspondence: Dr. Gouda M El-Labban Department of Surgery, Faculty of Medicine, Suez Canal University, Ismailia, Egypt. E-mail: ellabbang@yahoo.com

\section{Abstract}

We aimed to test the hypothesis that Minimally Invasive Video-assisted Thyroidectomy (MIVAT) affords comparable safety and efficacy as to the open conventional surgery, when dealing with patients with unilateral thyroid nodules or follicular lesions, in terms of cosmetic results, intraoperative and postoperative complications, postoperative pain and hospital stay. MATERIALS AND METHODS: This was a single-blinded randomised controlled trial comparing the MIVAT with conventional thyroidectomy. The primary endpoints of the study were measurement of postoperative pain after 24 and 48 hours from operation and self-rated patient satisfaction with cosmetic outcome three months postoperatively. The secondary outcome measures were operative time, incidence of temporary and permanent recurrent laryngeal nerve injury, postoperative haematoma formation, length of incision, and duration of hospital stay. RESULTS: Operative time was significantly less with open thyroidectomy than with MIVAT, while MIVAT was associated with less pain 24 hours postoperatively. Blood loss did not reach significance between procedures. Comparisons between the two procedures with regard to pain scores after 24 and 48 hours, respectively, depicted statistically significant differences in favour of the MIVAT after 24 hours. MIVAT was associated with less scarring and more satisfactory cosmetic results. There were statistically no significant differences between both procedures for the presence of transient recurrent laryngeal nerve palsy and hypoparathyroidism. CONCLUSIONS: MIVAT is a safe procedure that produces outcomes, in view of short-term adverse events, similar to those of open thyroidectomy, and is superior in terms of immediate postoperative pain and cosmetic results.
Key words: Thyroid surgery, minimally invasive

DOI: 10.4103/0972-9941.59307

\section{INTRODUCTION}

Minimally invasive surgery for the neck is one of the newest and most interesting applications. Many reports exist on the use of this technique in thyroid surgery, particularly with regard to eliminating the unattractive scars sometimes caused by conventional surgery. ${ }^{[1-11]}$ Minimal-access thyroid surgery was conceived primarily in Europe and Asia. A number of groups ${ }^{[11-17]}$ have made pioneering contributions to this field. While a variety of minimally invasive approaches have been endorsed, the technique most widely practiced in North America is minimally invasive video-assisted thyroidectomy (MIVAT), as originally described by Miccoli et al..$^{[12]}$ As with many new surgical techniques, adoption of MIVAT in the United States has been slow and somewhat deliberate. Increasingly, however, high-volume thyroid surgical centers have embraced this approach, and modestsized case series have been published, detailing their experiences. ${ }^{[18-19]}$ A more comprehensive reflection of the North American experience with MIVAT, shows that consolidated data have been compiled prospectively at four academic medical centers, paying specific attention to the safety and feasibility of this approach.[20] Several surgeons have reported their experiences with minimally invasive and video-assisted surgery of the neck. ${ }^{[2,12,13,21-40]}$ Although all these evidence-based data reported short- and long-term outcome data after 
endoscopic resections for different thyroid diseases, and clearly showed advantages in comparison with the traditional procedures, mini-invasive thyroid surgery has not been accepted yet. ${ }^{[3,19,41-46]}$ One of the reasons for this initial refusal is partly due to the technical difficulty of endoscopic resection requiring adequate training both in open and endoscopic procedures before safely performing gland resection. ${ }^{[46]}$

Minimally invasive video-assisted thyroidectomy (MIVAT) has the potential to offer similar advantages over conventional thyroidectomy. However, almost a decade after the early descriptions of endoscopic thyroidectomy, MIVAT remains in the early phase of its evolution, with a variety of techniques practiced in a relatively small number of specialist centers internationally. ${ }^{[47]}$ While the feasibility of MIVAT approaches has been well documented, few studies have observed these techniques in the setting of a randomised trial. Minimally invasive approaches have demonstrated some advantages in terms of cosmetic and pain outcomes. ${ }^{[13,42]}$ While this approach appears anecdotally to have benefits over conventional thyroidectomy, a randomised clinical trial is needed to avoid the selection bias, which is inherent in retrospective studies and surgical case series. ${ }^{[48]}$

The aim of this study was to compare the outcomes of MIVAT with conventional surgery in patients presenting with unilateral thyroid nodules or follicular lesions.

\section{MATERIALS AND METHODS}

\section{Study design}

A single-blinded, randomised clinical trial comparing MIVAT with conventional hemithyroidectomy was undertaken within the Suez Canal University Hospital. The trial was approved by the Faculty of Medicine, Suez Canal University Research Ethics Committee, and written informed consents were obtained from all participants prior to entry into the trial. The study population included those patients with unilateral thyroid nodules or follicular lesions requiring hemithyroidectomy for further histological diagnosis. Patients with small solitary toxic thyroid nodules were also eligible for participation. Patients were considered for randomisation if they had unilateral nodular disease, with a maximum nodule diameter of less than or equal to $3.0 \mathrm{~cm}$ and were able to give informed consent. The participants were considered ineligible if preoperative fine needle cytology showed thyroid carcinoma, if the nodule diameter was greater than $3.0 \mathrm{~cm}$, active thyroiditis was evident, or there was a history of previous neck surgery or head and neck irradiation.

\section{Operative technique}

Patients were randomised to undergo diagnostic hemithyroidectomy by either MIVAT or the conventional method. All the patients were blinded to the allocated procedure preoperatively. The procedure was performed by the same surgeon, and surgeon was aware of the procedure type at the time of randomisation. All patients underwent preoperative fiberoptic laryngoscopy to assess vocal cord movement. Both procedures were performed by a standardised technique. All patients had local infiltration of subcutaneous tissues beneath the incision with $5 \mathrm{ml}$ of Marcaine, $0.5 \%$ with adrenaline.

The technique for MIVAT has been described previously by Miccoli et al. ${ }^{[13]}$ The gasless video-assisted thyroid surgery was used. The patients were operated under general endotracheal anesthesia.

The patient was placed in a supine position and the neck was not hyperextended. Depending on the nodule size, a $2 \mathrm{~cm}$ or $2.5 \mathrm{~cm}$ horizontal skin incision was made $2 \mathrm{~cm}$ above the clavicle. An upper flap was created by subplatysmal dissection and elevated to create a tent-like working space, which provided a comfortable space for simultaneous insertion of a $3.3-\mathrm{mm} 0^{\circ}$ laparoscope and instruments through the same skin incision. With endoscopic assistance, subplastysmal dissection was carefully performed to avoid bleeding. The cervical linea alba was divided longitudinally as far up as the thyroid cartilage. The overlying strap muscles were dissected off the thyroid. The strap muscles on the affected side were retracted using an Army-Navy retractor to expose the thyroid and hold open the dissection space. A 10 Fr. suction catheter was attached to the scope for continuous suction of warm air in the wound, to prevent blurry scope optics. The middle thyroid vein or the small veins between the jugular vein and thyroid were divided with the help of a harmonic scalpel. An Allis tissue forceps was applied to the upper portion of the 
thyroid, allowing a downward and lateral traction of the thyroid. The avascular space between the upper pole of the thyroid and the cricothyroid muscle was opened to identify the external branch of the superior laryngeal nerve. The superior thyroid vessels were selectively isolated and divided using the harmonic scalpel. Subsequent to dividing the superior thyroid vessels, the upper portion of the thyroid was gently extracted from the incision using an Allis forceps. Gentle traction over the thyroid enabled the gland to be extracted without rupture. Then the inferior thyroid artery was exposed, and the parathyroid glands and recurrent laryngeal nerve were identified clearly. The inferior thyroid artery was ligated and not divided on the thyroid capsule, distal to its supply of the parathyroid glands. The thyroid was freed from the trachea by ligating the small vessels and dissecting the ligament of Berry. The isthmus was then dissected from the trachea and divided using the harmonic scalpel. The specimen excised was extracted from the wound and a small suction drain was left inside. The wound was closed with absorbable sutures.

Conventional hemithyroidectomy was performed by utilising a 5-6 cm Kocher incision and division of the ipsilateral strap muscles. After this exposure, the operative technique mirrored that used in the MIVAT approach. A standard dressing was applied for both MIVAT and conventional cases, with adhesive surgical tape placed horizontally across the neck. Patients were observed in the 24-hour ward and discharge was planned for the morning of the following day.

\section{Outcome measures}

The primary endpoints of the study were measurement of postoperative pain after 24 and 48 hours of the operation and self-rated patient satisfaction with the cosmetic outcome, three months postoperatively. Postoperative pain scores were measured using a 10 -point visual analogue scale (VAS) postoperatively. A higher numeric pain score represented more severe pain. Satisfaction with cosmetic outcome was measured at the follow-up using a 10-point VAS.

The secondary outcome measures were operative time, incidence of temporary and permanent recurrent laryngeal nerve injury, postoperative haematoma formation, length of incision, and duration of hospital stay.
The operative time was measured from initiation of the incision to conclusion of the skin closure, to the nearest minute. Recurrent laryngeal nerve function was assessed with preoperative and postoperative fiberoptic laryngoscopy. Postoperative haematoma was considered significant if it required return to the operating room (OR) for evacuation. Incision length was measured to the closest millimeter at the final follow up.

\section{RESULTS}

\section{Patient characteristics}

The clinical characteristics of the patients in the two groups were similar. There was a predominance of females in both groups, and the mean nodule size was equivalent between the groups, without any significant difference. The clinical characteristics are summarised in Table 1.

\section{Surgical treatment}

No patients in the MIVAT group required conversion to conventional surgery. The operative time as measured from the initiation of skin incision to the conclusion of subcuticular closure was greater for the MIVAT cases when compared with the conventional $(P<0.0001)$ cases. On an average, the MIVATS procedure had an operative time that was 16 minutes greater in duration than the conventional procedure. There were no significant differences in the estimated intraoperative blood loss or length of hospital stay. There were two patients who developed temporary recurrent laryngeal nerve paralysis in the MIVAT group and one in the conventional group. There was only one patient with permanent recurrent laryngeal nerve injury in the MIVAT group. No patient required return to the operating room for evacuation of haematoma. The operative details and complication rates are summarised in Table 2.

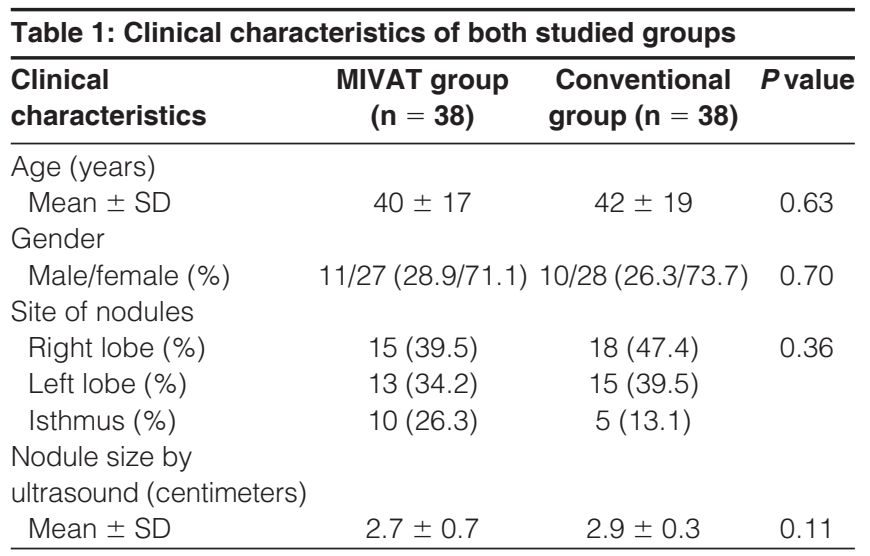




\begin{tabular}{|c|c|c|c|}
\hline Surgical details & $\begin{array}{l}\text { MIVAT group } \\
\quad(n=38)\end{array}$ & $\begin{array}{l}\text { Conventional } \\
\text { group }(n=38)\end{array}$ & $P$ value \\
\hline \multicolumn{4}{|l|}{$\begin{array}{l}\text { Duration of procedure } \\
\text { (minutes) }\end{array}$} \\
\hline Mean \pm SD & $62 \pm 21$ & $46 \pm 5$ & $<0.0001^{\star *}$ \\
\hline \multicolumn{4}{|l|}{$\begin{array}{l}\text { Estimated blood loss } \\
\text { (milliliter) }\end{array}$} \\
\hline $\begin{array}{l}\text { Intraoperative } \\
\text { Mean } \pm S D\end{array}$ & $39 \pm 13.3$ & $36.0 \pm 19.5$ & 0.44 \\
\hline $\begin{array}{l}\text { Postoperative } \\
\text { Mean } \pm \text { SD }\end{array}$ & $15 \pm 2.5$ & $14.2 \pm 1.7$ & 0.11 \\
\hline \multicolumn{4}{|c|}{$\begin{array}{l}\text { Duration of hospital stay } \\
\text { (days) }\end{array}$} \\
\hline Mean \pm SD & $1.2 \pm 0.4$ & $1.04 \pm 0.5$ & 0.13 \\
\hline \multicolumn{4}{|l|}{$\begin{array}{l}\text { Recurrent laryngeal } \\
\text { nerve dysfunction }\end{array}$} \\
\hline $\begin{array}{l}\text { Temporary } \\
\text { injury (\%) }\end{array}$ & $2(5.3)$ & $1(2.6)$ & 0.88 \\
\hline $\begin{array}{l}\text { Permanent } \\
\text { injury (\%) }\end{array}$ & $1(2.6)$ & 0 & 0.99 \\
\hline \multicolumn{4}{|l|}{ Haematoma } \\
\hline $\begin{array}{l}\text { Significant requiring } \\
\text { return to OR }\end{array}$ & 0 & 0 & 1.00 \\
\hline Insignificant & 0 & 0 & 1.00 \\
\hline \multicolumn{4}{|l|}{ Wound infections } \\
\hline No. (\%) & $2(5.3)$ & $2(5.3)$ & 1.00 \\
\hline \multicolumn{4}{|l|}{ Hypoparathyroidism } \\
\hline No. $(\%)$ & $2(5.3)$ & $2(5.3)$ & 1.00 \\
\hline
\end{tabular}

\section{Outcome measures}

Pain scores as measured on the 10-point VAS were significantly less in the MIVAT group after the first postoperative day when compared with the conventional group. The mean pain score after day one was 2.6 for the MIVAT group and 3.4 for the conventional group. There was no statistically significant difference in pain scores when measured 48 hours postoperatively $(P>0.05)$. The mean doses of intramuscular diclofenac sodium given after operation were significantly lower in the MIVAT group ( $40 \mathrm{mg}$ ) when compared with the conventional group (66 mg) $(P<0.0001)$. Three months postoperatively, participants in the MIVAT group reported a significantly greater satisfaction with the cosmetic outcome of their procedure compared to the conventional group. The mean satisfaction rating for the MIVAT group was 9.1 versus 4.9 for the conventional group on a scale of 1 to 10 , with 10 representing the best possible outcome. In the MIVAT group, there was a significantly smaller incision length compared to the conventional group $(3.2 \pm 0.9$ versus $5.4 \pm 0.7 \mathrm{~cm}$, respectively). The outcome data for pain scores and satisfaction with cosmetic appearance are summarised in Table 3.

\begin{tabular}{lccc}
\hline $\begin{array}{l}\text { Table 3: Outcomes after thyroidectomy treatment in both } \\
\text { studied groups }\end{array}$ & $\begin{array}{c}\text { MIVAT } \\
\text { group } \\
(\mathbf{n}=\mathbf{3 8})\end{array}$ & $\begin{array}{c}\text { Conventional } \\
\text { group } \\
\mathbf{( n = 3 8 )}\end{array}$ & $\boldsymbol{P}$ value \\
\hline Outcomes & & & \\
& $2.6 \pm 0.2$ & $3.4 \pm 0.6$ & $<0.0001^{* *}$ \\
\hline $\begin{array}{l}\text { VAS pain outcomes } \\
\text { Pain score after 24 hours }\end{array}$ & $1.7 \pm 0.1$ & $1.8 \pm 0.4$ & 0.14 \\
$\begin{array}{l}\text { Pain score after 48 hours } \\
\text { Dose of analgesic }\end{array}$ & & & \\
$\begin{array}{l}\text { consumption } \\
\text { postoperatively (diclofenac) } \\
\text { Mean } \pm \text { SD (mg) }\end{array}$ & $40 \pm 7.3$ & $66 \pm 12$ & $<0.0001^{* *}$ \\
$\begin{array}{l}\text { Satisfaction with cosmetic } \\
\text { results three months } \\
\text { postoperatively } \\
\text { Mean } \pm \text { SD }\end{array}$ & $9.1 \pm 0.5$ & $4.9 \pm 0.6$ & $<0.0001^{* *}$ \\
$\begin{array}{l}\text { Incision length (centimeters) } \\
\text { Mean } \pm \text { SD }\end{array}$ & $3.2 \pm 0.9$ & $5.4 \pm 0.7$ & $<0.0001^{* *}$ \\
\hline
\end{tabular}

\section{DISCUSSION}

This study shows that in patients with small thyroid nodules the minimally invasive approach to thyroidectomy has some advantages over conventional thyroidectomy. The benefits of the MIVAT technique were demonstrated by less pain in the early postoperative period and superior cosmetic results at the three-month follow-up. The MIVAT approach represents a refinement in operative technique for thyroidectomy, which is applicable to small symptomatic nodules, toxic nodules, and follicular lesions, requiring further histological assessment.

The advantages of minimally invasive thyroidectomy have been demonstrated by other groups. As in this study, the major benefits center on reduction in pain and improvement in cosmetic results. ${ }^{[13,15,45,49-52]}$ The majority of these studies have evaluated the MIVAT technique.

The operative time for MIVAT remains greater than that of conventional surgery, a finding which is common to a number of studies of minimally invasive approaches to the thyroid. ${ }^{[23,42,45]}$ With greater experience, it is probable that operative times for MIVAT will decrease, particularly with the refinement of electrothermal vessel sealing devices, which have now become the preferred method for vessel control and dissection in open and minimally invasive thyroidectomy. This technology, in addition to the fact that MIVAT minimises the amount of unnecessary dissection required to expose the thyroid, will probably result in the decrease in operative time in 
the future. We hypothesise that the smaller skin incision and decreased area of dissection associated with MIVAT, results in less disruption of the cutaneous nerve supply, thus translating to less postoperative pain. To avoid the potential problem of information bias influencing the reporting of pain and cosmetic scores, we blinded patients preoperatively. Postoperatively, there is the potential for bias in reporting of pain scores from the MIVAT group; however, the combined reduction after day one pain scores and analgesic requirement suggests that the improvement effect is real. Similar benefits in terms of pain reduction have been reported in other series. ${ }^{[45,48,53]}$

\section{CONCLUSION}

MIVAT is a safe procedure that produces outcomes; in view of short-term adverse events, similar to those of open thyroidectomy, it needs a longer operative time to be accomplished, but is superior in terms of immediate postoperative pain and cosmetic results.

\section{REFERENCES}

1. Miccoli P, Pinchera A, Cecchini G, et al. Minimally invasive video-assisted parathyroid surgery for primary hyperparathyroidism. J Endocrinol Invest 1997;20:429-30.

2. Ohgami M, Ishii S, Arisawa Y, et al. Scarless endoscopic thyroidectomy: Breast approach for better cosmesis. Surg Laparosc Endosc Percutan Tech 2000;10:1-4.

3. Miccoli P, Bendinelli C, Vignali E, et al. Endoscopic parathyroidectomy: Report of an initial experience. Surgery 1998;124:1077-9.

4. Hüscher G, Chiodini S, Napolitano C, Recher A. Endoscopic right thyroid lobectomy. Surg Endosc 1997;11:877.

5. Yeung C, Ng T, Kong K. Endoscopic thyroid and parathyroid surgery. Surg Endosc 1997;11:1135.

6. Henry F, Defechereux T, Gramatica L. Endoscopic parathyroidectomy via a lateral neck incision. Ann Chir 1999;53:302-6.

7. Gagner M. Endoscopic subtotal parathyroidectomy in patients with primary hyperparathyroidism. Br J Surg 1996;83:875.

8. Naitoh T, Gagner M, Garcia-Ruiz A. Endoscopic endocrine surgery in the neck: An initial report of endoscopic subtotal parathyroidectomy. Surg Endosc 1998;12:202-6.

9. Gottlieb A, Sprung J, Zheng XM, Gagner M. Massive subcutaneous emphysema and severe hypercapnia in a patient during endoscopic transcervical parathyroidectomy using carbon dioxide insufflation. Anesth Analg 1997;84:1154-6.

10. Shimizu K, Akira S, Jasmi Y, et al. Video-assisted neck surgery: Endoscopic resection of thyroid tumors with a very minimal neck wound. J Am Coll Surg 1999;188:697-703.

11. Bellantone R, Lombardi P, Raffaelli M, Rubino F, Boscherini M, Perilli W. Minimally invasive, totally gasless video-assisted thyroid lobectomy. Am J Surg 1999;177:342-3.

12. Miccoli P, Berti P, Conte M, Bendinelli C, Marcocci C. Minimally invasive surgery for thyroid small nodules: Preliminary report. J Endocrinol Invest 1999;22:849-51.

13. Miccoli P, Berti P, Raffaelli M, Materazzi G, Baldacci S, Rossi G.
Comparison between minimally invasive video-assisted thyroidectomy and conventional thyroidectomy: A prospective randomized study. Surgery 2001;130:1039-43.

14. Miccoli P, Berti P, Materazzi G, Minuto M, Barellini L. Minimally invasive video-assisted thyroidectomy: Five years of experience. J Am Coll Surg 2004;199:243-8.

15. Bellantone R, Lombardi CP, Bossola M, et al. Video-assisted vs conventional thyroid lobectomy: A randomized trial. Arch Surg 2002;137:301-4.

16. Palazzo F, Sebag F, Henry F. Endocrine surgical technique: Endoscopic thyroidectomy via the lateral approach. Surg Endosc 2006;20:339-42.

17. Ikeda Y, Takami H, Niimi M, Kan S, Sasaki Y, Takayama J. Endoscopic thyroidectomy by the axillary approach. Surg Endosc 2001;15:1362-4.

18. Terris J, Chin E. Clinical implementation of endoscopic thyroidectomy in selected patients. Laryngoscope 2006;116:1745-8.

19. Ujiki B, Sturgeon C, Denham D, Yip L, Angelos P. Minimally invasive video-assisted thyroidectomy for follicular neoplasm: Is there an advantage over conventional thyroidectomy? Ann Surg Oncol 2006;13:182-6.

20. Terris J, Angelos P, Steward L, Simental A. Minimally invasive video-assisted thyroidectomy. Arch Otolaryngol Head Neck Surg 2008;134:81-4.

21. Shimizu K. Minimally invasive thyroid surgery. Best Pract Res Clin Endocr Metab 2001;15:123-37.

22. Shimizu K, Akira S, Tanaka S. Video assisted neck surgery: Endoscopic resection of benign thyroid tumor aiming at scarless surgery on the neck. J Surg Oncol 1998;69:178-80.

23. Ikeda Y, Takami H, Sasaki Y, Takayama J, Niimi M, Kan S. Comparative study of thyroidectomies: Endoscopic surgery vs conventional open surgery. Surg Endosc 2002;16:1741-5.

24. Ikeda Y, Takami H, Tajima G, Sasaki Y, Takayama J, Kurihara H, et al. Direct mini-incision thyroidectomy. Biomed Pharmacother 2002;56:60-3.

25. Ikeda Y, Takami H, Tajima G, Sasaki Y, Takayama J, Kurihara H, et al. Total endoscopic thyroidectomy: Axillary or anterior chest approach. Biomed Pharmacother 2002;56:72-8.

26. Ikeda Y, Takami H, Sasaki Y, Takayama J, Kurihara H. Are there significant benefits of minimally invasive endoscopic thyroidectomy? World J Surg 2004;28:1075-8.

27. Miccoli P. Minimally invasive surgery for thyroid and parathyroid diseases. Surg Endosc 2002;16:3-6.

28. Miccoli P, Bellantone R, Mourad M, Walz M, Raffaeli M, Berti P. Minimally invasive video-assisted thyroidectomy: Multi-istitutional experience. World J Surg 2002;26:972-5.

29. Miccoli P, Berti P, Raffaeli M, Conte M, Materazzi G, Galleri D. Minimally invasive video-assisted thyroidectomy. Am J Surg 2001;181:567-70.

30. Miccoli P, Berti P, Raffaeli M, Materazzi G, Conte M, Galleri D. Impact of Harmonic Scalpel on operative time durino video-assisted thyroidectomy. Surg Endosc 2002;16:663-6.

31. Miccoli P, Elisei R, Materazzi G, Capezzone M, Galleri D, Pacini F, et al. Minimally invasive video-assisted thyroidectomy for papillary carcinoma: A prospective study of its completeness. Surgery 2002;132:1070-4.

32. Berti P, Materazzi G, Conte M, Galleri D, Miccoli P. Visualization of the external branch of the superior laryngeal nerve during video-assisted thyroidectomy. J Am Coll Surg 2002;194:573-4.

33. Mourad M, Pugin F, Elias B, Coche E, Squifflet JP, Malais J, et al. Contributions of the video-assisted approach to thyroid and parathyroid surgery. Acta Chir Belg 2002;102:323-7.

34. Musella M, Lombardi S, Caiazzo P, Milone F, Di Palma R, De Franciscis S, et al. La chirurgia video-assistita della tiroide: Note di tecnica e analisi dei risultati. Ann Ital Chir 2003;1:3-5.

35. Bellantone R, Lombardi C, Raffaeli M, Alesina P, De Crea C, Traini E, et al. Video-assisted thyroidectomy for papillary thyroid carcinoma. Surg Endosc 2003;17:1604-8. 
36. Bellantone R, Lombardi C, Raffaeli M, Boscherini M, De Crea C, Traini E. Video-assisted thyroidectomy. J Am Coll Surg 2002;194:610-4.

37. Lombardi C, Raffaeli M, Modesti C, Boscherini M, Bellantone R. Video-assisted thyroidectomy under local anesthesia. Am J Surg 2004; 187:515-8.

38. Ruggieri M, Straniero A, Pacini F, Mariuolo A, Mascaro A, Genderini M. Video-assisted surgery of the thyroid diseases. Eur Rev Med Pharmacol Sci 2003;7:91-6.

39. Ruggieri M, Straniero A, Pacini F, Mariuolo A, Mascaro A, Genderini M. Comparison between video-assisted thyroidectomy and conventional thyroidectomy: Preliminary aspects. Policlinico J Surg 2003;110:11-7.

40. Ruggieri M, Straniero A, Genderini M, D’Armiento M, Gargiulo P, Fumarola A, et al. The minimally invasive open video-assisted approach in surgical thyroid diseases. BMC Surg 2005;5:9.

41. Miccoli P, Minuto N, Ugolini C, Pisano R, Fosso A, Berti P. Minimally invasive video-assisted thyroidectomy for benign thyroid disease: An evidence-based review. World J Surg 2008;32:1333-40.

42. Hegazy A, Khater A, Setit E, Amin A, Kotb Z, El Shafei A, et al. Minimally invasive video-assisted thyroidectomy for small follicular thyroid nodules. World J Surg 2007;31:1743-50.

43. Gal I, Solymosi T, Szabo Z, Balint A, Bolgar G. Minimally invasive videoassisted thyroidectomy and conventional thyroidectomy: A prospective randomized study. Surg Endosc 2008;22:2445-9.

44. Alvarado R, McMullen T, Sidhu B, Delbridge W, Sywak S. Minimally invasive thyroid surgery for single nodules: An evidence-based review of the lateral mini-incision technique. World J Surg 2008;32:1341-8.

45. Sgourakis G, Sotiropoulos C, Neuhäuser M, Musholt J, Karaliotas C, Lang $\mathrm{H}$. Comparison between minimally invasive video-assisted thyroidectomy and conventional thyroidectomy: Is there any evidencebased information? Thyroid 2008;18:721-7.
46. Duh QY. Presidential address: Minimally invasive endocrine surgerystandard of treatment or hype? Surgery 2003;134:849-57.

47. Gagner M, Inabnet B. Endoscopic thyroidectomy for solitary thyroid nodules. Thyroid 2001;11:161-3.

48. Sywak S, Yeh W, McMullen T, Stalberg P, Low H, Alvarado R, et al. A randomized controlled trial of minimally invasive thyroidectomy using the lateral direct approach versus conventional hemithyroidectomy. Surgery 2008;144:1016-22.

49. Cavicchi O, Piccin O, Ceroni R, Caliceti U. Minimally invasive non-endoscopic thyroidectomy. Otolaryngol Head Neck Surg 2006;135:744-7.

50. Lombardi P, Raffaelli M, Princi P, De Crea C, Bellantone R. Video-assisted thyroidectomy: Report of a 7-year experience in Rome. Langenbecks Arch Surg 2006;391:174-7.

51. Terris J, Haus M, Nettar K, Ciecko S, Gourin G. Prospective evaluation of endoscopic approaches to the thyroid compartment. Laryngoscope 2004;114:1377-82.

52. Terris J, Bonnett A, Gourin G, Chin E. Minimally invasive thyroidectomy using the Sofferman technique. Laryngoscope 2005;115:1104-8.

53. Del Rio P, Berti M, Sommaruga L, Arcuri F, Cataldo S, Sianesi M. Pain after minimally invasive videoassisted and after minimally invasive open thyroidectomy-results of a prospective outcome study. Langenbecks Arch Surg 2008;393:271-3.

Cite this article as: El-Labban GM. Minimally invasive video-assisted thyroidectomy versus conventional thyroidectomy: A single-blinded, randomized controlled clinical trial. J Min Access Surg 2009;5:97-102.

Date of submission: 13/08/09, Date of acceptance: 07/11/09

Source of Support: Nil, Conflict of Interest: None declared.

\section{Author Help: Reference checking facility}

The manuscript system (www.journalonweb.com) allows the authors to check and verify the accuracy and style of references. The tool checks the references with PubMed as per a predefined style. Authors are encouraged to use this facility, before submitting articles to the journal.

- The style as well as bibliographic elements should be $100 \%$ accurate, to help get the references verified from the system. Even a single spelling error or addition of issue number/month of publication will lead to an error when verifying the reference.

- Example of a correct style Sheahan P, O'leary G, Lee G, Fitzgibbon J. Cystic cervical metastases: Incidence and diagnosis using fine needle aspiration biopsy. Otolaryngol Head Neck Surg 2002;127:294-8.

- Only the references from journals indexed in PubMed will be checked.

- $\quad$ Enter each reference in new line, without a serial number.

- Add up to a maximum of 15 references at a time.

- If the reference is correct for its bibliographic elements and punctuations, it will be shown as CORRECT and a link to the correct article in PubMed will be given.

- If any of the bibliographic elements are missing, incorrect or extra (such as issue number), it will be shown as INCORRECT and link to possible articles in PubMed will be given. 